backnen Thränen von fahler Farbe, in Ansehen und Geruch dem smyrnaschen gleichend. Beim Trocknen verliert es 7,6 $\frac{0}{0}$. An Morphin gab es 5,02 \%. Die Benutzung auf Opium hindert keineswegs die spätere Gewinnung des Oels aus dem Samen. - Simon will aus dem Opium von Algier $12 \%$ Morphin erbalten haben. Es ist aber unsicher, ob dieses rein gewesen.

In einer Mittheilung von Lia u taud an dieselbe Akademie hat $\mathrm{L}$. über bengalisches Opium nach den Angaben von Wallich und Monad in Calcutta Nachricht gegeben, nach welchen eine Sorte Opium im dortigen Handel die Bezeichnung chinesisches erhalte und durchschnittlich 10,50 Morphin enthalte. (Institut No. 513. - Pharm. Centralbl. No. 53.) $B$.

\title{
Santonin als Arzneimittel und seine Darstellung.
}

Auch nach Callou d's Beobachtungen ist das Santonin ein vorziigliches Mittel gegen Würmer. Die beste Gabe für Kinder soll $30-50$ Centigramm sein, also circa $5-8$ Gran täglich. Calloud giebt es in Tabletten aus Santon. 4 Gr., Sach. albiss. 150 Gr., G. Tragac. 2 Gr. M. f. I. a. tab.

Darstellung des Santonins nach Calloud.

30 Kilogramm (60PId.) Sem. Cynae erhitzt man in einem Kessel mit Wasser zum Sieden, fällt mit Kalkmilch den Farbstoff und sättigt zugleich das Santonin, das roth ist, presst den Rückstand, zieht diesen nochmals aus, lässt bei den $A b$ kochungen vereinigt absetzen, giesst $a b$, dampft cin, klärt die Flüssigkeit, seihet sie durch, dampft sodann weiter ab und setzt derselben in einer Schale einen kleinen Ueberschuss Salzsäure hinzu, worauf nach 24 Stunden das Santonin sich abscheidet. Es wird mit schwachem Weingeist gewaschen, ausgepresst, in kochendem Alkohol gelöst, mit Thierkohle behandeit und krystallisirt. Nach längerer Ruhe und weiterem Eindunsten und etwa nöthigem Zusatze von Kalkmilch erhält man eine noch grössere Ausbeute von Santonin. Die Vorschrift liasst viel zu wünsehen übrig und es ist desshalb dankenswerth, dass Mialhe es unternommen hat sie zu prüfen. (Bullet de therap $X X$ V. 202. Pharm. Centralbl. No. 53. 1×43.) B.

Bemerkungen zu der neuen Methode der StickstoffBestimmung.

Reiset hat bekanntlich der Akademie der Wissenschaften in Paris eine Abhandlung eingereicht, worin er 
zu beweisen sucht, dass die Methode der Stickstoffbestimmung von Will und Varrentrapp mit 2 Fehlerquellen behaftet sei. Die Ursache der ersten soll die scin, dass der Stickstoff der atmosphärischen Luft bei der Zersetzung stickstoffhaltiger Materien durch ein Alkalihydrat Antheil an der Ammoniakbildung nimmt, in Folge dessen man immer den Stichstoffgehalt zu hoch finden müsse. Ferner sollen sehr viele stickstofffreie Materien beim Zusammenschmelzen mit den Alkalihydraten nicht unbeträchtlich Anımoniak erzeugen Hierher gehört besonders Zucker, welcher von Will und Varrentrap vorgeschlagen ist, stickstoffreichen Substanzen zuzumischen, um die heftige Ammoniakentwickelung zu vermindern.

H. Will weist nun durch mehrere Versuche nach, dass das Stickgas der Atmosphäre sich mit Wasserstoff in statu nascenti keineswegs verbinden kann. Er erhiclt bei seinen Versuchen allerdings äusserst geringe Mengen Ammoniak, die jedoch eine andere Quelle hatten und durchaus vermieden werden, wenn das Alkalihydrat kur'z vor der Anwendung erhitzt wird. - R eiset giebt ferner an, dass Eisen beim Erhitzen mit Kalilauge bis $130^{\circ}$ und bei Luftzutritt Ammoniak entwickele, was seinen Grund wahrscheinlich darin habe, dass das von $R$ ciset angewandte Alkali elwas salpetersaures Salz enthielt.

Die zweite von $R$ eiset aufgefundene Fehlerquelle besteht nach ihm darin, dass ein Theil des Platinchlorids zu Chlorür reducirt wird, wenn man die salzsaure Flüssigkeit, die oft fluissige Kohlenwasserstoffe enthält, damit im Wasserbade zur Trockne verdunstet. Hiernach muisste man immer zuviel Stickstoff erhalten, da dieses Platinchlorür in Aether und Alkohol unlöslich ist, und was um so mehr eintreten müsste, je mehr Kohlenwasserstoffe vorhanden sind. Will konnte bei seinen Versuchen jedoch nie eine Reduction des Platinchlorids beim Verdampfen im Wasserbade wahrnehmen, und giebt an, dass man die Bildung der Kohlenwasserstoffe fast ganz vermeiden könne, wenn der vordere Theil der Röhre stark im Glühen erhalten wird. (Annal. der Ch. u. Pharm. B. 15. p. 95.) Meurer.

\section{Die Silphionpflanze der Alten und das Bu Nefa} der Araber.

Römer und Griechen legten auf die medicinischen Eigenschaften einer Pflanze, die sie Silphion nannten, einen sehr hohen Werth. Die Pflanze kam hauptsüchlich aus Afrika und man nannte sie deshalb den "Schatz Afrikas". 